Pesq. Vet. Bras. 36(12):1186-1189, dezembro 2016

DOI: $10.1590 / \mathrm{S} 0100-736 \mathrm{X} 2016001200008$

\title{
Avaliação de parâmetros bioquímicos séricos em Tartarugas- -da-Amazônia (Podocnemis expansa) mantidas em cativeiro ${ }^{1}$
}

\author{
Leandro A. Fonseca ${ }^{2 *}$, Natasha L. Maia², Fabrícia M. Girardi², Wilson P. \\ Carvalho Filho ${ }^{2}$, Filippe G. Pimentel ${ }^{3}$ e Fábio R. Braga ${ }^{4}$
}

\begin{abstract}
Fonseca L.A., Maia N.L., Girardi F.M.Carvalho Filho W.P., Pimentel F.G. \& Braga F.R. 2016. [Evaluation of serum biochemical parameters in Amazon turtles (Podocnemis expansa) hatchlings kept in captivity.] Avaliação de parâmetros bioquímicos séricos em Tartarugas-da-Amazônia (Podocnemis expansa) mantidas em cativeiro. Pesquisa Veterinária Brasileira 36(12):1186-1189. Departamento de Veterinária, Universidade Federal de Viçosa, Avenida Peter Henry Rolfs s/n, Campus Universitário, Viçosa, MG 36570-000, Brazil. E-mail: leandroabreu@ufv.br

Blood samples from the giant river turtle kept in captivity were analyzed in order to evaluate the serum biochemical constituents and relate to what has been reported by other researchers, beyond the purpose of generating further information, given the paucity of data involving this species. The turtle eggs were from the state of Tocantins and were obtained from direct sampling in their natural habitat. After being collected the eggs were kept in incubators and then the puppies were kept in tanks. Samples were collected after chemical restraint of these animals by intracardiac puncture or cardiocentesis. The samples were centrifuged to obtain serum. Biochemical analyzes were processed by kinetic and colorimetric methods, as described by the manufacturer, and the values obtained were: calcium $7.0 \pm 1.9 \mathrm{mg} / \mathrm{dL}$, phosphorus $2.8 \pm 1.2 \mathrm{mg} / \mathrm{dL}$, uric acid $1.8 \pm 0.8 \mathrm{mg} / \mathrm{dL}$, BUN $10.4 \pm 3.9 \mathrm{mg} / \mathrm{dL}$, alanine aminotransferase (AST) $75.5 \pm 33.6 \mathrm{IU} / \mathrm{L}$, total protein $1.9 \pm 0.8 \mathrm{~g} /$ $\mathrm{dL}$, triglycerides $22.9 \pm 9.8 \mathrm{mg} / \mathrm{dL}$ and cholesterol $45.3 \pm 19.7 \mathrm{mg} / \mathrm{dL}$. It was observed that the values of the evaluated blood components are similar to those found by other researchers in serum biochemical studies with samples of Podocnemis expansa. During this study we observed the paucity of published data on blood parameters of Podocnemis genus, especially P. expansa species, which confirmed the high relevance of the development of further research involving this topic.
\end{abstract}

INDEX TERMS: Podocnemis, serum biochemistry, giant river turtle.

RESUMO-- Amostras de sangue de Tartaruga-da-Amazônia mantidas em cativeiro foram analisadas com o propósito de avaliar os constituintes bioquímicos séricos e de relacionar ao que já foi relatado por outros pesquisadores, além de gerar mais informações, tendo em vista a escassez de dados envolvendo a espécie estudada. Foram utilizados 35 animais, com idade entre 3 e 7 meses, os quais foram

\footnotetext{
${ }^{1}$ Recebido em 9 de junho de 2015.

Aceito para publicação em 5 de julho de 2016.

${ }^{2}$ Departamento de Veterinária, Universidade Federal de Viçosa (UFV), Avenida P.H. Rolfs s/n, Campus Universitário, Viçosa, MG 36570-000, Brasil.*Autor para correspondência: leandroabreu@ufv.br

${ }^{3}$ Departamento de Bioquímica Agrícola, UFV, Avenida P.H. Rolfs s/n, Campus Universitário, Viçosa, MG 36570-000, Brasil.

${ }^{4}$ Universidade de Vila Velha (UVV), Av. Comissário José Dantas de Melo 21, Boa Vista, Vila Velha, ES 29102-920, Brasil.
}

contidos fisicamente para coleta de sangue em tubo sem anticoagulante. As análises bioquímicas foram processadas através de métodos cinéticos (enzimas) e colorimétricos (demais análises), e os valores médios obtidos foram: cálcio $7,0 \pm 1,9 \mathrm{mg} / \mathrm{dL}$, fóforo $2,8 \pm 1,2 \mathrm{mg} / \mathrm{dL}$, ácido úrico $1,8 \pm 0,8 \mathrm{mg} / \mathrm{dL}$, uréia $10,4 \pm 3,9 \mathrm{mg} / \mathrm{dL}$, alanina aminotransferase (AST) 75,5 $\pm 33,6 \mathrm{UI} / \mathrm{L}$, proteína total $1,9 \pm 0,8 \mathrm{~g} / \mathrm{dL}$, triglicerídeos $22,9 \pm 9,8 \mathrm{mg} / \mathrm{dL}$ e colesterol $45,3 \pm 19,7 \mathrm{mg} /$ dL. Observou-se que os valores dos componentes séricos avaliados assemelham-se aos que foram encontrados por outros pesquisadores em estudos bioquímicos séricos com Podocnemis expansa e outras tartarugas de água doce. Importante ressaltar que, no decorrer deste estudo observou-se a escassez de dados publicados sobre parâmetros sanguíneos de tartarugas do gênero Podocnemis, especialmente a espécie Podocnemis expansa, o que corroborou a 
alta relevância do desenvolvimento de mais pesquisas que envolvam a questão.

TERMOS DE INDEXAÇÃO: Podocnemis, bioquímica sérica, Tartaruga-da-Amazônia.

\section{INTRODUÇÃO}

As tartarugas do gênero Podocnemis pertencem à família Podocnemididae, tendo cinco espécies distribuídas nas regiões norte e centro-oeste do Brasil (Ferreira Júnior \& Castro 2003). A espécie Podocnemis expansa, também conhecida como tartaruga gigante da Amazônia, é o maior quelônio de água doce da América do Sul, medindo entre 75,0 e 107,0 cm de comprimento e tem uma ampla distribuição pelas bacias do Amazonas e Orinoco, ocorrendo na Colômbia, Venezuela, Guianas, Equador, Peru, Bolívia e Brasil, chegando a alcançar a região central do território brasileiro (Fantin et al. 2008).

No Brasil, o uso de carne e ovos dessas tartarugas pelo povo ribeirinho da Amazônia na alimentação ocorre desde o início da colonização, portanto, o risco de extinção desta espécie existe e sendo ela protegida por leis federais. Como consequência, a criação comercial desta tartaruga foi introduzida no estado do Amazonas por autoridades ambientais, em 1999, em uma tentativa de manter populações naturais da espécie preservadas (Ferreira Júnior \& Castro 2003). Apesar disso, vários criatórios não regulamentados expõem os animais à precárias condições de manejo, o que explica o aparecimento de processos patológicos (Santos et al. 2005).

Afecções hepáticas de causas variadas, rinites, pneumonias, broncopneumonias infecciosas, endoparasitoses e hemoparasitoses estão entre as principais enfermidades que acometem as tartarugas, sendo as possíveis responsáveis por diferentes graus de anemia e até mesmo a morte destes animais (Rossini et al. 2012). Além disso, variações fisiológicas dos constituintes séricos de répteis podem ocorrer devido à alimentação, tempo de apnéia, variações na temperatura corporal, disponibilidade de água, ciclo reprodutivo, estação do ano, idade e hibernação (Christopher et al. 1999).

Nesse contexto, há ainda pouca informação sobre a parâmetros de avaliação clínicos e laboratoriais da Tartaruga-da-Amazônia, especialmente no que diz respeito ao seu perfil hematológico e bioquímico (Oliveira-Júnior et al. 2009). Sendo assim, o objetivo desse trabalho é fornecer informações a respeito dos parâmetros bioquímicos de Tartarugas-da-Amazônia nascidas e mantidas em cativeiro.

\section{MATERIAL E MÉTODOS}

Foram coletados ovos no município de São Miguel do Araguaia $\left(13^{\circ} 12^{\prime} \mathrm{S}\right.$ e $\left.50^{\circ} 35^{\prime} \mathrm{W}\right)$, estado de Goiás durante a temporada de desova das tartarugas-da-amazônia (Podocnemis expansa). A coleta foi feita no início da manhã, no período mais fresco do dia, para evitar a desidratação dos ovos. Os ninhos escolhidos foram aqueles desovados no mesmo dia da coleta, o que foi confirmado pelos rastros recentes das fêmeas e pelo substrato úmido proveniente de fluidos liberados durante a desova ou pela visualização das fêmeas no ato da desova.
Os ovos foram transportados em caixas plásticas contendo vermiculita expandida (argilomineral com grande capacidade de absorção e retenção de líquidos) umedecida com água, para evitar a desidratação, e choques durante o transporte. Os ovos foram transportados até a base do Projeto Quelônios da Amazônia do RAN-IBAMA, e posteriormente enviados até o criatório experimental, onde foram mantidos em incubação até a eclosão. Após a eclosão dos ovos, os animais foram mantidos em compartimento com água e suporte para termo-regulação, recebendo diariamente, ad libitum, ração para peixe com $28 \%$ de proteína bruta.

Para avaliação dos constituintes bioquímicos, foram utilizados 35 animais, com idade entre 3 e 7 meses, os quais foram mensurados o comprimento curvilíneo de carapaça (CCC) e contidos fisicamente para coleta de sangue em tubo sem anticoagulante. As amostras de sangue foram obtidas através de coletas por via intracardíaca e encaminhadas para processamento, sendo centrifugadas a 5000 RPM durante 10 minutos.

Os exames bioquímicos foram realizados em aparelho semi-automático ${ }^{5}$ utilizando kits comerciais ${ }^{6}$. Foram mensurados os níveis séricos de cálcio, fósforo, ácido úrico, uréia, aspartato aminotransferase (AST), proteínas totais, triglicerídeos e colesterol, além do índice de relação cálcio:fósforo (Ca:P). A análise bioquímica sérica foi feita utilizando metodologia cinética para determinação das atividades enzimáticas e colorimétrica para os demais testes, conforme descrição do fabricante.

Após a obtenção dos dados foi realizada análise de normalidade pelo teste de Kolmogorov-Smirnov. Os valores máximos e mínimos ("outliers") foram identificados e descartados, assim, os dados restantes produziram uma distribuição normal (Horn et al. 2001). Para cada parâmetro foram estabelecidos a média, desvio padrão, erro padrão e intervalo de referência (definido com intervalo de confiança de 95\%), sendo estabelecido um nível de 0,05 de significância.

Todas as etapas do experimento foram devidamente autorizadas pelo ICMBIO/SISBIO/Brasil, permissão número 12308-1. 0 protocolo experimental foi registrado e autorizado pela CEUA - Comissão de ética para o uso de animais em pesquisa da Universidade Vila Velha pelo número 105/2010.

\section{RESULTADOS E DISCUSSÃO}

Os animais avaliados apresentaram CCC variando de 5,6 a 7,9 cm, com média e desvio padrão de 6,4 $\pm 1,1 \mathrm{~cm}$. De acordo com Pires \& Guimarães (2006), Casal \& Orós (2007) e Oliveira-Júnior et al. (2009), variações laboratoriais são relatadas em diferentes espécies de tartarugas devido a alguns fatores tais como a qualidade do ambiente aquático, localização geográfica, variação genética, estado nutricional, sexo e idade. Os valores de referência estabelecidos para os parâmetros bioquímicos de P. expansa neste estudo são apresentados no Quadro 1.

Os valores obtidos na presente pesquisa foram comparados aos valores obtidos por outros pesquisadores. Os níveis séricos de cálcio foram semelhantes aos encontrados por Santos et al. (2005), o qual realizou seu experimento limitando-se à utilização apenas da espécie Podocnemis expansa, entretanto, estes níveis foram inferiores aos citados por Mader (1996), Campbell (2004) e Thrall et al. (2015) que descrevem níveis séricos de cálcio para répteis, não se limitando apenas à espécie desta pesquisa.

\footnotetext{
${ }^{5}$ Bioplus - BIO200.

${ }^{6}$ Bioclin Quibasa.
} 
Quadro 1. Valores de referência de parâmetros bioquímicos séricos em tartarugas da Amazônia (P. expansa) $(\mathrm{n}=35)$, mantidas em cativeiro

\begin{tabular}{lccccc}
\hline \multicolumn{1}{c}{ Parâmetros } & $\mathrm{n}$ & Média + DP & \multicolumn{2}{c}{ Intervalo de Confiança } & \begin{tabular}{c} 
Erro \\
\cline { 5 - 6 }
\end{tabular} \\
& & & $\begin{array}{c}\text { Limite } \\
\text { inferior }\end{array}$ & $\begin{array}{c}\text { Limite } \\
\text { superior }\end{array}$ & \\
\hline Cálcio (mg/dL) & 35 & $7,0+1,9$ & 6,34 & 7,65 & 0,60 \\
Fósforo (mg/dL) & 31 & $2,8+1.2$ & 2,35 & 3,24 & 0,37 \\
Ácido úrico (mg/dL) & 23 & $1,8+0,8$ & 1,45 & 2,14 & 0,25 \\
Uréia (mg/dL) & 20 & $10,4+3,9$ & 8,57 & 12,22 & 1,23 \\
AST (UI/L) & 31 & $75,5+33,6$ & 63,17 & 87,82 & 10,62 \\
Proteína total (g/dL) & 35 & $1.9+0.8$ & 1.62 & 2.17 & 0.25 \\
Triglicerídeos (mg/dL) & 28 & $22,9+9,8$ & 19,09 & 26,70 & 3,09 \\
Colesterol (mg/dL) & 24 & $45,3+19,7$ & 36,98 & 53,61 & 6,22
\end{tabular}

Em répteis, dentre os distúrbios metabólicos nutricionais, a doença óssea metabólica é o mais comum em quelônios, consequência da alimentação inadequada fornecida a estes animais (Fowler \& Cubas 2001). Esse distúrbio ocorre principalmente em animais em crescimento, e é geralmente resultado do desequilíbrio nos níveis de cálcio e fósforo, consumo insuficiente de cálcio, deficiência de vitamina D ou da falta de exposição dos animais a raios ultravioleta (Cubas et al. 2014). Répteis jovens com hiperparatireoidismo nutricional secundário, normalmente apresentam doença óssea metabólica, com osteodistrofia fibrosa e fraturas ósseas (Thrall et al. 2015). Fêmeas reptilianas, durante o desenvolvimento do ovo, apresentam hipercalcemia em resposta à atividade reprodutiva e aos níveis de estrógeno (Campbell 2004).

Com relação ao nível sérico de fósforo, foi observado que os resultados encontrados foram semelhantes aos citados por Mader (1996), Campbell (2004), Santos et al. (2005) e Thrall et al. (2015), que utilizaram animais sadios para estabelecer os parâmetros séricos. Segundo Thrall et al. (2015), o excesso de fósforo na dieta de répteis pode levar à hipocalcemia, sendo assim, torna-se importante a determinação dos valores de referência nesta espécie para realizar um diagnóstico correto. Devido à variação de manejo alimentar a que esses animais podem estar expostos, os níveis séricos de cálcio e fósforo devem ser equilibrados através de dieta apropriada, e se possível, acompanhados por análises bioquímicas periódicas. $\mathrm{O}$ cálculo da relação Ca:P obteve um índice médio de 2,5 para a espécie e faixa etária estudadas.

Os valores de ácido úrico encontrados, assim como os de fósforo, estiveram dentro do intervalo proposto por Mader (1996), Santos et al. (2005) e Thrall et al. (2015). 0 ácido úrico e os sais de uratos são resultantes do metabolismo protéico do organismo (Cubas et al. 2014). Altos níveis de ácido úrico se acumulam no sangue, causando precipitação destes elementos em tecidos e articulações, e consequentemente um processo patológico importante. Além disso, pode ocorrer a precipitação de cristais formados nos túbulos renais, levando à insuficiência renal. Quelônios afetados apresentam anorexia, edema, podendo evoluir para óbito (Fowler \& Cubas 2001).

Segundo Thrall et al. (2015), répteis podem desenvolver hiperuricemia, podendo estar ligada à doença ou consumo recente de dieta com alto teor protéico, portanto, o jejum antes da coleta das amostras se torna fundamental. A con- centração plasmática de ácido úrico tende a ser maior em répteis carnívoros do que em herbívoros. Nesses animais podemos ter a doença primária, que advém da produção excessiva de ácido úrico ou secundária, quando existe uma enfermidade adquirida que interfere na produção e excreção normais deste elemento. Répteis apresentam como causas mais comuns de doença secundária, a inanição, doença renal, desidratação grave e prolongada e conteúdo excessivo de purinas na dieta. Animais mantidos em cativeiro recebem frequentemente dietas ricas em proteínas, consequentemente após algum tempo, distúrbios como a hiperuricemia e doença renal podem estar presentes, sendo assim, o monitoramento periódico dos níveis séricos de ácido úrico em animais criados em cativeiro deve ser realizado.

Os resultados de uréia encontrados estiveram dentro do intervalo descrito por Thrall et al. (2015), porém inferiores aos valores encontrados por Santos et al. (2005). Além disso, esses resultados foram superiores aos de citados por Mader (1996) e Oliveira-Júnior et al. (2009). Em répteis, doença renal ou pré-renal pode ser sugerida quando há uma elevação dos valores séricos de uréia. No entanto, esta elevação também pode ser observada em outras condições, como por exemplo, em decorrência de uma dieta rica em proteínas, o que torna esta elevação não tão confiável (Cubas et al. 2014).

Segundo Campbell (2004), apesar da creatinina ser um componente normal da urina de mamíferos, geralmente a concentração sérica da mesma é considerada de pouco valor diagnóstico para doença renal de répteis. Isso porque na maioria dos répteis a quantidade formada é insignificante $(<1 \mathrm{mg} / \mathrm{dL})$, justificando o motivo da não abordagem nesse estudo.

Os níveis de AST encontrados estão de acordo com o intervalo proposto por Mader (1996), Campbell (2004), Santos et al. (2005) e Thrall et al. (2015). Segundo Thrall et al. (2015), o tecido hepático dos répteis apresenta altas atividades de LDH e AST. Altas concentrações de AST são encontradas nos músculos e fígado, e elevações dos valores desta enzima no soro ou plasma sugerem doença hepática ou lesões musculares (Mader 1996). Em répteis, doenças generalizadas como septicemia ou toxemia podem ser causas de aumento na atividade plasmática desta enzima (Mader 1996, Cubas et al. 2014).

As proteínas plasmáticas diferiram dos valores encontrados por outros pesquisadores. Os resultados foram inferiores aos propostos por Santos et al. (2005), porém, semelhantes aos que foram encontrados por Oliveira-Júnior et al. (2009), ambos autores trabalharam somente com a espécie $P$. expansa. No presente estudo, foi observado que os níveis séricos de proteína variam entre os autores, sendo assim, pode-se constatar que existe a necessidade de mais estudos para esse exame. Conforme Mader (1996) e Thrall et al. (2015), a hipoproteinemia está comumente associada à má nutrição, entretanto, outras causas são relatadas como má absorção, má digestão, enteropatias com perda de proteínas, doença hepática ou renal crônicas e hemorragia grave.

Os resultados de triglicerídeos e colesterol se assemelharam aos resultados obtidos por Oliveira-Júnior et al. 
(2009) e foram inferiores aos de Santos et al. (2005). A hiperlipidemia (aumento da concentração sérica de triglicerídeos, colesterol, ou de ambos) pode ser resultado de processos fisiológicos ou patológicos (Thrall et al. 2015). Em animais com diabetes mellitus, obstruções biliares, pancreatite, hipotireoidismo ou que recebem dietas ricas em carboidratos e gorduras, os níveis séricos de colesterol podem estar aumentados. No entanto, animais que recebem dietas com baixos valores energéticos, podem apresentar níveis séricos de colesterol diminuídos (González \& Silva 2006). Os processos patológicos que resultam em aumento do nível sérico deste elemento são os mesmos originados da hipercolesterolemia. Segundo Thrall et al. (2015), a forma de hipolipidemia mais comum em animais é a hipocolesterolemia, a qual está normalmente associada a doenças que resultam em insuficiência hepática.

\section{CONCLUSÕES}

Valores dos constituintes bioquímicos séricos de Tartarugas-da-Amazônia (Podocnemis expansa) devem ser utilizados e divulgados com maior frequência a fim de auxiliar na diferenciação de condições fisiologicas e de doença.

Os resultados do presente estudo contribuem para a obtenção dos valores de referência para tartarugas do espécie Podocnemis expansa mantidas em cativeiro, e podem auxiliar na correção e adequação do manejo alimentar dos animais, diminuindo a ocorrência de processos patológicos.

Agradecimentos.- Ao Professor Dr. Paulo Dias Ferreira Júnior por ceder os animais para a pesquisa; à Fundação de Amparo à Pesquisa do Espírito Santo (FAPES); à Fundação de Amparo à Pesquisa do Estado de Minas Gerais (FAPEMIG) e ao Conselho Nacional de Desenvolvimento Científico e Tecnológico (CNPq) pelo apoio.

\section{REFERÊNCIAS}

Campbell T.W. 2004. Blood biochemistry of lower vertebrates. American College of Veterinary Pathologists and American Society for Veterinary Clinical Pathology, Middletown, WI, USA.
Casal A.B. \& Orós J. 2007. Morphologic and cytochemical characteristics of blood cells of juvenile loggerhead sea turtles (Caretta caretta). Res. Vet. Sci. 82(2):158-165.

Christopher M.M., Berry K.H., Wallis I.R., Nagy K.A., Henen B.T. \& Peterson C.C. 1999. Reference intervals and physiologic alterations in hematological and biochemical values of free-raging desert tortoises in Mojave desert. J. Wildl. Dis. 35(2):212-238.

Cubas Z.S., Silva J.C.R. \& Catão-Dias J.L. 2014. Tratado de Animais Selvagens. $2^{\underline{a}}$ ed. Roca, São Paulo. 1354p.

Fantin C., Viana L.S., Dos Santos Monjeló L.A. \& Farias I.P. 2008. Polyandry in Podocnemis unifilis (Pleurodira; Podocnemididae), the vulnerable yellow-spotted Amazon River turtle. Amphibia-Reptilia 29(4):479-486.

Ferreira Júnior P.D. \& Castro P.T.A. 2003. Controle geológico das áreas de nidificação de Podocnemis expansa e Podocnemis unifilis no Rio Javaés, Ilha do Bananal, Brasil. Acta Amazônica 33(3):445-468.

Fowler M.E. \& Cubas Z.S. 2001. Biology, Medicine, and Surgery of South American Wild Animals. Iowa State University Press, Ames. 536p.

González F.H.D. \& Silva S.C. 2006. Introdução à Bioquímica Clínica Veterinária. $2^{\mathrm{a}}$ ed. UFRGS, Porto Alegre. 358p.

Horn P.S., Feng L., Li Y. \& Pesce A.J. 2001. Effect of outliers and nonhealthy individuals on reference interval estimation. Clin. Chemistry 47(12):2137-145.

Mader D.R. 1996. Reptile Medicine and Surgery. 4th ed. W.B. Saunders, Philadelphia. 531p.

Oliveira-Júnior A.A., Tavares-Dias M. \& Marcon J.L. 2009. Biochemical and hematological reference ranges for Amazon freshwater turtle, Podocnemis expansa (Reptilia: Pelomedusidae), with morphologic assessment of blood cells. Res. Vet. Sci. 86(1):146-151.

Pires G.R. \& Guimarães J.E. 2006. Hemograma e determinação da proteína plasmática total de tartarugas marinhas da espécie Caretta caretta (Linnaeus, 1758), criadas em cativeiro, Praia do Forte, Município de Mata de São João, Bahia. Braz. J. Vet. Res. Anim. Sci. 43(3):348-353.

Rossini M., Blanco P.A., Marín E., Comerma-Steffensen S. \& Zerpa H. 2012. Haematological values of post-laying Arrau turtle (Podocnemis expansa) in the Orinoco River, Venezuela. Res. Vet. Sci. 92(1):128-131.

Santos A.L.Q., Malta T.S., Mundim A.V., Alves Júnior J.R.F. \& Carvalho S.F.M. 2005. Variação dos constituintes bioquímicos sanguíneos de tartarugas-da-amazônia (Podocnemis expansa Schweigger, 1812) (Testutinata) mantidas em criatório comercial. Archs Vet. Sci. 10(3):1-8.

Thrall M.A., Baker D.C., Campbell T.W., Denicola D., Fettman M.J., Lassen E.D., Rebar A. \& Weiser G. 2015. Hematologia e Bioquímica Clínica Veterinária. 2a ed. Roca, São Paulo. 688p. 